\title{
Matrizes e animações: uma aplicação no ensino médio*
}

\author{
$\underline{\text { Maiara A. C. Valentim }}^{\dagger} \quad$ José Carlos de Souza Júnior \\ Instituto de Ciências Exatas, ICEx, UNIFAL-MG, \\ 37130-000, Alfenas, MG \\ E-mail: maicoimbra@hotmail.com, jcsouzajr@uol.com.br,
}

\author{
Daniela C. Lima \\ Escola Estadual Judith Vianna \\ 37130-000, Alfenas, MG \\ E-mail: danielacristina@yahoo.com.br
}

\section{RESUMO}

Muitas vezes os educadores na área de Matemática encontram dificuldades em desenvolver determinados conteúdos exibindo a aplicação dos mesmos ou contextualizando-os adequadamente para seus alunos. Por este motivo, várias vezes o ensino é realizado mediante apenas definições e resolução de exercícios. No entanto, de acordo com D’Ambrósio [1] deve-se abordar problemas significativos ao invés de situações artificiais e repetitivas. Ainda, segundo Fonseca [2] contextualizar não é abolir a técnica e a compreensão, mas ultrapassar esses aspectos e entender fatores externos aos que normalmente são explicitados na escola de modo que os conteúdos matemáticos possam ser compreendidos dentro do panorama histórico, social e cultural que o constituíram.

São muitos os motivos pelos quais os professores não conseguem preparar aulas diferenciadas. Dentre estes motivos estão a falta de tempo devido ao número excessivo de aulas, o comodismo, a falta de apoio da instituição, a falta de incentivo à capacitação docente, a ausência de recursos, entre outros agravantes que levam sobretudo à desmotivação dos professores e, consequentemente, a dos alunos. Dentre os conteúdos de Matemática que, em geral, são abordados sem aplicação ou contextualização, destaca-se o estudo de matrizes. Sobre isto, Sanches [3] afirma que quase sempre o ensino-aprendizagem de matrizes é voltado para a transmissão de regras, descontextualizado da realidade e da própria Matemática, em total descompasso com os avanços tecnológicos e com as tendências atuais em Educação Matemática.

Além disto, o estudo de matrizes não é abordado no Currículo Básico Comum do Estado de Minas Gerais, bem como em outras matrizes relevantes como a matriz de referência do Exame Nacional do Ensino Médio. Com isto, esse conteúdo acaba sendo pouco trabalhado na escola pública de forma que alguns professores o fazem superficialmente, apenas para que os alunos não concluam o ensino básico sem conhecê-lo.

Buscando uma contextualização do tema para o ensino médio, na intenção de auxiliar o professor em sala de aula e na tentativa de motivar os alunos, foi desenvolvido, como parte integrante das atividades realizadas pelo Programa Institucional de Bolsas de Iniciação a Docência (PIBID), o minicurso "Aplicações com Matrizes: matrizes e animações", sendo que o presente trabalho tem como objetivo relatar a atividade e os resultados obtidos.

O minicurso ocorreu no laboratório de informática da Universidade Federal de Alfenas com alunos do ensino médio de uma escola pública, cujo objetivo era promover uma atividade em que os alunos pudessem aprender a utilizar o software livre GeoGebra, realizando algumas operações com matrizes e ainda,

\footnotetext{
${ }^{*}$ O presente trabalho foi realizado com apoio financeiro da Fundação de Amparo a Pesquisa do Estado de Minas Gerais (FAPEMIG) e do Programa Institucional de Bolsa de Iniciação à Docência (PIBID), da Coordenação de Aperfeiçoamento de Pessoal de Nível Superior (CAPES), Brasil.

†bolsista de Iniciação à Docência PIBID/CAPES
} 
conhecer um pouco sobre animações, desempenhando uma atividade que abordava a transformação geométrica de rotação. Com o intuito de fazer um comparativo identificando o conhecimento prévio sobre aplicações com matrizes e o posicionamento dos alunos em relação ao tema e posteriormente sobre a atividade, foi realizado um questionário diagnóstico inicial e outro questionário final. Após o primeiro questionário, cada aluno teve acesso ao software, sendo familiarizado com o mesmo, conhecendo alguns de seus recursos e potencialidades, e a um caderno de acompanhamento digital.

Na primeira atividade, inicialmente foram feitas algumas definições, relembrando o que é uma matriz, como são feitas as operações com matrizes e definida a transposta de uma matriz. Em seguida, os alunos aprenderam a realizar operações com matrizes no Geogebra. Após esta atividade, houve uma breve discussão sobre a criação de animações dando ênfase na movimentação dos personagens e ao cenário. Foi abordado ainda, o tópico imagens digitais, realizando algumas explicações. Para ilustrar a discussão feita, os alunos assistiram a um curta metragem do filme Carros, produzido pela Pixar Animation Studios, e após a análise da cena em que o personagem Mate assusta vários tratores, foi introduzido o conceito de transformações geométricas abordando especificamente rotação.

Partindo de uma imagem no plano, o objetivo da segunda atividade era levar os alunos à compreensão de como funciona a rotação dessa imagem. Para tanto, fez-se a discussão de como relacionar as coordenadas de um ponto antes, e após a rotação do sistema de coordenadas, por um ângulo $\theta$, chegando-se a conclusão que um ponto com coordenadas $(x, y)$, após uma rotação de um ângulo $\theta$ no sentido antihorário, passaria a ter as seguintes coordenadas $(x \cos \theta-y \operatorname{sen} \theta, x \operatorname{sen} \theta+y \cos \theta)$. A discussão foi finalizada representando a relação encontrada através da representação matricial:

$$
\left(\begin{array}{cc}
\cos \theta & -\operatorname{sen} \theta \\
\operatorname{sen} \theta & \cos \theta
\end{array}\right) \cdot\left(\begin{array}{l}
x \\
y
\end{array}\right)=\left(\begin{array}{l}
x \cos \theta-y \operatorname{sen} \theta \\
x \operatorname{sen} \theta+y \cos \theta
\end{array}\right)
$$

Após essa discussão, os alunos construíram no GeoGebra a rotação da imagem de um dos tratores do filme Carros, utilizando os conceitos aprendidos, sendo instruídos a inserir os comandos e a realizar as operações necessárias com as matrizes.

Ao término da atividade, os alunos realizaram o questionário final que além de retomar algumas perguntas iniciais os questionava também sobre a aplicação da atividade. Os resultados obtidos na comparação dos questionários confirmaram que o estudo de matrizes só havia sido feito de forma convencional. Além disto, antes do minicurso, que abordou nas discussões algumas das diversas utilidades de matrizes, os estudantes disseram não ver utilidade neste assunto fora da sala de aula e acreditavam que sua aplicação estava relacionada apenas a computadores e restrita as ciências exatas. Todavia, após o minicurso, os alunos relataram que a atividade, bem como a utilização de um software estimulou o interesse pelo conteúdo e auxiliou na melhoria do aprendizado, uma vez que eles conseguiram visualizar melhor através da manipulação e assim compreender conceitos matemáticos juntamente com a importância das matrizes.

Desta forma, acredita-se que a aplicação tenha atingido seus objetivos tornando-se um recurso para o professor, incentivando-o a utilizar novas práticas em sala de aula e ainda servindo como uma motivação para os alunos, auxiliando também em uma melhor compreensão de matrizes e suas aplicações. Cabe ressaltar que os alunos que mais participaram das atividades, questionando e mostrando interesse por ela, foram os que demonstravam certa aversão a Matemática e dificuldade na disciplina.

Palavras-chave: Educação Matemática, Geometria Dinâmica, Transformações Geométricas.

\section{Referências}

[1] U. D’Ambrósio, “Etnomatemática”, Ática, São Paulo, 1998.

[2] M. C. F. R., Fonseca, "Por que ensinar Matemática”, Presença Pedagógica, Belo Horizonte, 1995.

[3] M. H. F. Sanches, "Efeitos de uma estratégia diferenciada de ensino do conceito de matrizes", Dissertação de mestrado, Faculdade de Educação Unicamp, 2002. 